\title{
Antifungal resistance in patients with Candidaemia: a retrospective cohort study
}

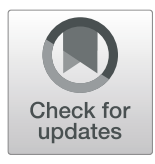

\author{
Namareq F. Aldardeer ${ }^{1 *}$ (D, Hadiel Albar ${ }^{1}$, Majda Al-Attas ${ }^{1}$, Abdelmoneim Eldali', Mohammed Qutub', \\ Ashraf Hassanien $^{3}$ and Basem Alraddadi ${ }^{1,4}$
}

\begin{abstract}
Background: Candidaemia is the most common form of invasive candidiasis. Resistant Candida blood stream infection (BSI) is rising, with limitations on the development of broader-spectrum antifungal agents worldwide. Our study aimed to identify the occurrence of antifungal-resistant candidaemia and the distribution of these species, determine the risk factors associated with antifungal resistance and evaluate the association of antifungalresistant candidaemia with the length of intensive care unit (ICU) and hospital stay and with 30-day mortality.

Methods: A retrospective cohort study was conducted at King Faisal Specialist Hospital and Research Centre, Jeddah, Saudi Arabia. Adult patients diagnosed with candidaemia from January 2006 to December 2017 were included.

Results: A total of 196 BSIs were identified in 94 males (49.74\%) and 95 females (50.26\%). C. glabrata was the most commonly isolated Candida species, with 59 (30\%), followed by C. albicans with 46 (23\%). Susceptibility data were available for 122/189 patients, of whom 26/122 (21\%) were resistant to one or more antifungals. C. parapsilosis with available sensitivity data were found in 30/122 isolates, of which 10/30 (33\%) were resistant to fluconazole. Risk factors significantly associated with antifungal-resistant candidaemia included previous echinocandin exposure (odds ratio $(\mathrm{OR})=1.38 ; 95 \%$ confidence interval $(\mathrm{Cl})(1.02-1.85) ; P=0.006)$ and invasive ventilation $(\mathrm{OR}=1.3 ; 95 \% \mathrm{Cl}$ $(1.08-1.57) ; P=0.005)$. The median length of ICU stay was 29 days [range 12-49 days] in the antifungal-resistant group and 18 days [range 6.7-37.5 days] in the antifungal-sensitive group $(P=0.28)$. The median length of hospital stay was 51 days [range 21-138 days] in the antifungal-resistant group and 35 days [range 17-77 days] in the antifungal-sensitive group $(P=0.09)$. Thirty-day mortality was $15(57.7 \%)$ and $54(56.25 \%)$ among the antifungalresistant and antifungal-sensitive groups, respectively $(\mathrm{OR}=1.01 ; 95 \% \mathrm{Cl}(0.84-1.21) ; P=0.89)$.
\end{abstract}

Conclusions: Our results indicate a high frequancy of non- C. albicans candidaemia. The rise in C. parapsilosis resistance to fluconazole is alarming. Further studies are required to confirm this finding.

Keywords: Antifungal resistance, Epidemiology, Risk factors, Candida parapsilosis, Mortality, Fluconazole resistance

\section{Background}

Systemic fungal infections have emerged as a significant public health problem [1]. Among hospitalized patients, candidaemia is the most common form of invasive candidiasis (IC), which accounts for $9 \%$ of all nosocomial bloodstream infections (BSIs) [2, 3]. In a 2014 United States (US) surveillance study, Candida species ranked as the seventh causative organism of healthcare-associated

\footnotetext{
* Correspondence: aldardeern@hotmail.com

${ }^{1}$ King Faisal Specialist Hospital and Research Center, Jeddah, Saudi Arabia

Full list of author information is available at the end of the article
}

BSIs [4]. Recent reports indicated that candidaemia is the third or fourth most common hospital-acquired BSI in US hospitals [5]. Candida species are considered the leading pathogen in many fungal infections affecting humans. Among 15 distinct Candida species causing human disease, C. albicans, C. glabrata, C. tropicalis, C. parapsilosis and C. krusei are the most common pathogens leading to IC [5].

Risk factors associated with antifungal resistance have been addressed in many studies. Previous fluconazole exposure, neutropenia and chronic kidney disease are known to contribute to C. albicans fluconazole resistance [6]. 
However, total parental nutrition, previous episodes of candidaemia and the presence of fluconazole-resistant isolates were mainly accompanied by echinocandin resistance [7]. In Saudi Arabia, many studies have described the distribution and risk factors for Candida BSI; however, there are no local studies on the risk factors associated with antifungal resistance and its effect on mortality. $C$. albicans were the most commonly isolated Candida among all studies conducted in Saudi Arabia [8-11]. Predisposing factors related to candidaemia occurrence were related to use of a central venous catheter, previous use of broad-spectrum antibiotics and complicated abdominal surgeries; the mortality rate was $43 \%$ for all candidaemia cases [9]. Therefore, our study was conducted to identify the occurrence of antifungal-resistant candidaemia, describe the distribution of Candida species among hospitalized patients with candidaemia, determine the risk factors associated with antifungal resistance and evaluate the association of antifungal resistance with length of ICU and hospital stay and with 30-day mortality.

\section{Methods}

\section{Setting and study design}

A retrospective cohort study was conducted at King Faisal Specialist Hospital and Research Centre, Jeddah, Saudi Arabia (KFSH\&RC-J), a 500-bed teaching and tertiary care hospital. The study was approved by the hospital institutional review board. Between January 2006 and December 2017, all adult patients 18 years old and above with isolated Candida BSI with or without other forms of IC were included. IC included disseminated hepatosplenic candidiasis, intra-abdominal candidiasis, Candida intravascular infection, osteoarticular candidiasis, Candida endophthalmitis, vulvovaginal candidiasis, Candida urinary tract infection, oropharyngeal candidiasis, oesophageal candidiasis or central nervous system candidiasis [5]. The study excluded patients under 18 years of age and those infected with IC alone in the absence of candidaemia. Patients with candidaemia were reviewed through hospital electronic charts. The REDCap system was used to collect patient information, such as patient demographics and comorbidities. Baseline characteristics and Candida distribution were assessed for all patients with Candida BSI. Patients with available susceptibility data were divided into two groups: antifungal-sensitive and antifungal-resistant; risk factor and mortality analyses were performed. Antifungal resistance was considered for any identified isolate with resistance to one or more antifungals based on the laboratory cut-off value of minimum inhibitory concentration (MIC).

The primary outcome was the occurrence of antifungal resistance among candidaemia patients over a 12-year study period. The secondary outcomes were the distribution of Candida BSI, the risk factors for antifungal resistance and the association of antifungal resistance with length of ICU and hospital stay and with 30-day mortality.

\section{Microbiology}

The identification of Candida BSI was consistent throughout the study period. Identification was performed by a blood culture test and processed by using the automated blood culture system BACTEC FX. The average incubation period was 5 days and reaches up to 21 days whenever candidaemia is suspected. The API 20C AUX Kit was used for identification and specification of yeast, and Sensititre YeastOne was used for susceptibility. The MICs for fluconazole, voriconazole, itraconazole, posaconazole, amphotericin B, flucytosine, caspofungin, anidulafungin and micafungin were interpreted based on the Clinical and Laboratory Standard Institute (CLSI M27-S4). As the interpretation of the amphotericin B susceptibility breakpoint has not yet been defined [12], our study did not address amphotericin B susceptibility testing for Candida BSI.

\section{Statistical analysis}

Data were analysed using SAS version 9.4. Descriptive statistics using the mean, median and interquartile range (IQR) were used for continuous variables. Frequencies and percentages were used for categorical variables. The chi-square test and Fisher's exact test were used to compare categorical variables. For risk factor analysis of antifungal resistance, we performed a univariate logistic regression analysis. For 30-day mortality, we performed univariate and multivariable analyses to identify factors associated with mortality. A $P$ value less than 0.05 was considered significant.

\section{Results}

From January 2006 to December 2017, a total of 196 Candida species were identified in 189 patients. Demographic characteristics and risk factors associated with resistant Candida BSI are listed in (Table 1). The most common Candida species during the study period was C. glabrata ( $n=59,30.1 \%)$. Distributions of Candida species are included in (Table 2). Table.

One hundred and twenty-two patients with antifungal susceptibility data were analysed in the candidaemia resistance risk factor analysis (Table 3); the percentage of antifungal resistance was $21 \%(26 / 122)$. Candidaemia with antifungal resistance was significantly more likely to develop among patients with previous echinocandin exposure (odds ratio (OR), 1.38; 95\% CI (1.02-1.85); $P=$ $0.006)$ and in patients who received invasive ventilation (OR, 1.3; 95\% CI (1.08-1.57); $P=0.005$ ).

Cross-resistance among azole antifungals was observed in our study. All strains resistant to 
Table 1 Baseline characteristics for patients with candida bloodstream infection (BSIs)

\begin{tabular}{|c|c|}
\hline Characteristics & $\begin{array}{l}\text { Number of Patients } \\
(N=189) \\
n(\%)\end{array}$ \\
\hline Mean Age (years) & $57.3 \pm 17.5$ \\
\hline \multicolumn{2}{|l|}{ Gender } \\
\hline Male & $94(49.74 \%)$ \\
\hline Female & $95(50.26 \%)$ \\
\hline Bacteremia co-infection & $79(41.8 \%)$ \\
\hline \multicolumn{2}{|l|}{ Baseline Comorbidities } \\
\hline Diabetes & $99(52.38 \%)$ \\
\hline Hypertension & $105(55.56 \%)$ \\
\hline Chronic kidney disease & $24(12.7 \%)$ \\
\hline Liver Cirrhosis & $33(17.46 \%)$ \\
\hline Cardiovascular diseases & $96(50.79 \%)$ \\
\hline Lung diseases & $52(27.51 \%)$ \\
\hline Human immunodeficiency virus & $3(1.59 \%)$ \\
\hline Solid organ transplantation & $8(4.23 \%)$ \\
\hline Hematological malignancy & $9(4.76 \%)$ \\
\hline Non hematological malignancy & $48(25.4 \%)$ \\
\hline Neutropenia ${ }^{a}$ & $25(13.23 \%)$ \\
\hline History of IV drug user & $3(1.59 \%)$ \\
\hline Blood/ Platelet transfusion & $135(71.43 \%)$ \\
\hline Recent hospital admission & $35(18.52 \%)$ \\
\hline \multicolumn{2}{|c|}{ Exposure to medication within 3 months ${ }^{\text {a }}$} \\
\hline Broad spectrum antibiotics & $182(96.3 \%)$ \\
\hline Polyene antifungal & $3(1.59 \%)$ \\
\hline Azole antifungal (Fluconazole) & $11(5.82 \%)$ \\
\hline Echinocandins & $38(20.11 \%)$ \\
\hline Corticosteroids & $86(45.5 \%)$ \\
\hline \multicolumn{2}{|c|}{ Exposure to medical procedures within 3 months } \\
\hline TPN & $20(10.58 \%)$ \\
\hline Central line insertion & 151 (79.89\%) \\
\hline Urine catheter & $148(78.31 \%)$ \\
\hline Invasive Ventilation & $100(52.91 \%)$ \\
\hline Surgery within 3 months & $77(40.74 \%)$ \\
\hline Gl & $38(49.35 \%)$ \\
\hline Non- Gl & $39(50.65 \%)$ \\
\hline Renal Replacement therapy & $66(34.92 \%)$ \\
\hline HD & $54(28.57 \%)$ \\
\hline PD & $4(2.12 \%)$ \\
\hline CRRT & $11(5.82 \%)$ \\
\hline SLID & $4(2.12 \%)$ \\
\hline
\end{tabular}

Total parental nutrition (TPN); Gastrointestinal (Gl); Hemodialysis (HD); Peritoneal dialysis (PD); Continuous renal replacement therapy (CRRT);

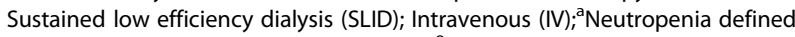
as an absolute neutrophil count of, $1.010^{9} / \mathrm{L}$ or less; $\mathrm{N}=$ total number of patients; $\mathrm{n}=$ number of patients or events
Table 2 Distribution of Candida Species over the study period

\begin{tabular}{ll}
\hline Candida isolates & $\begin{array}{l}\text { Total number of } \\
\text { isolates }(N=196) \\
\mathrm{n}(\%)\end{array}$ \\
\hline C. glabrata & $59(30.1)$ \\
C. albicans & $46(23.47)$ \\
C. parapsilosis & $38(19.39)$ \\
C. tropicalis & $35(17.86)$ \\
C. krusei & $6(3.06)$ \\
C. famata & $5(2.55)$ \\
C. lusitaniae & $1(0.51)$ \\
C. kefyr & $1(0.51)$ \\
C. dubliniensis & $1(0.51)$ \\
C. trichosporon asahii & $1(0.51)$ \\
Others & $3(1.53)$
\end{tabular}

voriconazole, including five strains of $C$. albicans, two strains of C. parapsilosis and one strain of C. tropicalis, were also resistant to fluconazole. Only two isolates were resistant to caspofungin, and three isolates were resistant to anidulafungin (Additional file 1: Tables S1 and S2).

The median (interquartile range [IQR]) length of ICU stay was 29 days [range 12-49 days] in the antifungalresistant group and 18 days [range 6.7-37.5 days] in the antifungal-sensitive group $(P=0.28)$. The median [IQR] length of hospital stay was 51 days [range 21-138 days] in the antifungal-resistant group and 35 days [range 1777 days] in the antifungal-sensitive group $(P=0.09)$. Thirty-day mortality was 15 (57.7\%) and 54 (56.25\%) for the antifungal-resistant and antifungal-sensitive groups, respectively $[\mathrm{OR}=1.01 ; 95 \% \mathrm{CI}(0.84-1.21) ; P=0.89]$ (Table 4).

In a multivariate logistic regression analysis used to assess factors associated with mortality in patients with candidaemia, the following factors were independently associated with mortality. Liver cirrhosis $[\mathrm{OR}=5.36 ; 95 \%$ CI (1.14-25.1)], non-haematological malignancy $[\mathrm{OR}=2.3 ; 95 \% \mathrm{CI}(1.01-5.25)]$, blood/ platelet transfusion $[\mathrm{OR}=4.4 ; 95 \%$ CI $(1.98-9.7)]$, central venous catheter $[\mathrm{OR}=4.37$; $95 \%$ CI $(1.79$ 10.66)] and invasive ventilation $[\mathrm{OR}=3.88 ; 95 \% \mathrm{CI}$ (1.82-8.29)] (Additional file 1: Table S3).

We performed a secondary analysis for patients with fluconazole-resistant $C$. parapsilosis to identify risk factors for resistance. Univariate analysis revealed that echinocandin exposure $[\mathrm{OR}=12.8 ; 95 \%$ CI $(2.01-81.10)]$, blood/platelet transfusion $[\mathrm{OR}=14.6 ; 95 \%$ CI $(1.54-$ 138.18)] and invasive ventilation $[\mathrm{OR}=2.1 ; 95 \% \mathrm{CI}$ (1.31-3.39)] were associated with fluconazole-resistant C. parapsilosis (Table 5). 
Table 3 Univariate regression analysis for risk factors associated with antifungal resistance candidemia

\begin{tabular}{|c|c|c|c|c|}
\hline & $\begin{array}{l}\text { Antifungal sensitive } \\
(N=96)\end{array}$ & $\begin{array}{l}\text { Antifungal resistance } \\
(N=26)\end{array}$ & OR $(95 \% \mathrm{Cl})$ & $P$ value \\
\hline $\begin{array}{l}\text { Age (years) } \\
\text { Mean } \pm S D\end{array}$ & $58.7 \pm 16.2$ & $56.5 \pm 20.29$ & & \\
\hline \multicolumn{5}{|l|}{ Gender, n (\%) } \\
\hline Male & $53(55.21)$ & $10(38.46)$ & $0.5\left(0.2 \_1.23\right)$ & 0.12 \\
\hline Female & $43(44.79)$ & $16(61.54)$ & & \\
\hline \multicolumn{5}{|l|}{ Comorbidities, n (\%) } \\
\hline Diabetes & $61(63.54 \%)$ & $15(57.69 \%)$ & $0.94\left(0.77 \_1.15\right)$ & 0.58 \\
\hline Hypertension & $56(58.33 \%)$ & $16(61.54 \%)$ & $1.02\left(0.85 \_1.23\right)$ & 0.76 \\
\hline Chronic Kidney disease & $14(14.58 \%)$ & $4(15.38 \%)$ & $1.01\left(0.77 \_1.32\right)$ & 0.91 \\
\hline Liver Cirrhosis & $10(10.42 \%)$ & $4(15.38 \%)$ & $1.11\left(0.78 \_1.57\right)$ & 0.48 \\
\hline Cardiovascular disease & $44(45.83)$ & $16(61.54)$ & 1.14(0.94_1.37) & 0.15 \\
\hline Lung diseases & $24(25 \%)$ & $6(23.08 \%)$ & $0.97\left(0.79 \_1.2\right)$ & 0.83 \\
\hline Solid organ transplantation & $2(2.08 \%)$ & $2(7.69 \%)$ & $1.59\left(0.59 \_4.26\right)$ & 0.15 \\
\hline Hematological malignancy & $2(2.08 \%)$ & 0 & & \\
\hline Non Hematological malignancy & $35(36.46 \%)$ & $2(7.69 \%)$ & $0.75\left(0.65 \_0.88\right)$ & 0.004 \\
\hline Neutropenia & $7(7.29 \%)$ & $4(15.38 \%)$ & $1.09\left(0.31 \_3.79\right)$ & 0.88 \\
\hline History of IV drug user & $2(2.08 \%)$ & $1(3.85 \%)$ & $1.18\left(0.52 \_2.65\right)$ & 0.6 \\
\hline \multicolumn{5}{|c|}{ 3-months exposure before candidemia } \\
\hline Blood/ Platelet transfusion & $60(62.5 \%)$ & $20(76.92 \%)$ & $1.14\left(0.95 \_1.36\right)$ & 0.16 \\
\hline Recent hospital admission & $20(20.83 \%)$ & $8(30.77 \%)$ & $1.13\left(0.87 \_1.45\right)$ & 0.28 \\
\hline Broad spectrum antibiotics & $90(93.75 \%)$ & $26(100 \%)$ & $1.28\left(1.16 \_1.42\right)$ & 0.19 \\
\hline Polyene antifungal & $3(3.13)$ & 0 & $0.78\left(0.71 \_0.85\right)$ & 0.36 \\
\hline Azole antifungal (fluconazole) & $8(8.33 \%)$ & $1(3.85 \%)$ & $0.87\left(0.68 \_1.12\right)$ & 0.43 \\
\hline Echinocandins & $19(19.79 \%)$ & $12(46.15 \%)$ & $1.38\left(1.02 \_1.85\right)$ & 0.006 \\
\hline Corticosteroids & $52(54.17 \%)$ & $19(73.08 \%)$ & $1.17\left(0.98 \_1.4\right)$ & 0.08 \\
\hline TPN & $13(13.54 \%)$ & $4(15.38 \%)$ & $1.03\left(0.78 \_1.36\right)$ & 0.81 \\
\hline Central catheter insertion & $71(73.96 \%)$ & $21(80.77 \%)$ & $1.07\left(0.88 \_1.31\right)$ & 0.47 \\
\hline Urine catheter & $73(76.04 \%)$ & $17(65.38 \%)$ & $0.88\left(0.69 \_1.12\right)$ & 0.27 \\
\hline Invasive Ventilation & $44(45.83 \%)$ & $20(76.92 \%)$ & $1.3\left(1.08 \_1.57\right)$ & 0.005 \\
\hline Previous surgery & $38(39.58 \%)$ & $14(53.85 \%)$ & $1.13\left(0.93 \_1.37\right)$ & 0.19 \\
\hline Gl & $21(55.26 \%)$ & $4(28.5 \%)$ & $1.08\left(0.88 \_1.31\right)$ & 0.42 \\
\hline Non- Gl & $17(44.7 \%)$ & $10(71.4 \%)$ & & \\
\hline Renal Replacement therapy & $36(37.5 \%)$ & $12(46.15 \%)$ & $1.08\left(0.88 \_1.31\right)$ & 0.42 \\
\hline $\mathrm{HD}$ & $26(27.08)$ & $12(46.15)$ & $1.21\left(0.96 \_1.54\right)$ & 0.06 \\
\hline PD & $3(3.13)$ & 0 & & \\
\hline CRRT & $9(9.38)$ & 0 & & \\
\hline SLID & $2(2.08)$ & $2(7.69)$ & $1.59(0.59-4.2)$ & 0.15 \\
\hline
\end{tabular}

Odd ratio (OR); Confidence interval (Cl); Total parental nutrition (TPN); Gastrointestinal (Gl); Hemodialysis (HD); Peritoneal dialysis (PD); Continuous renal replacement therapy (CRRT); Sustained low efficiency dialysis (SLID) $N=$ total number of patients; $n=$ number of patients or events

\section{Discussion}

Worldwide, there has been a notable shift away from $C$. albicans among patients with Candida BSI [13]. Our study showed a high frequency in non-C. albicans candidaemia (Fig. 1). These strains had a higher cost and length of hospital stay than C. albicans [14]. C. glabrata was the predominantly isolated Candida species among our candidaemia patients, representing $30 \%$ of cases, followed by C. albicans and C. parapsilosis. These findings differ from those of previous local studies. Two studies conducted in Saudi Arabia in a university hospital and armed force hospital between 1998 to 1999 
Table 4 Outcome analysis for patients with antifungal resistance candidemia

\begin{tabular}{|c|c|c|c|}
\hline & $\begin{array}{l}\text { Antifungal sensitive } \\
(N=96)\end{array}$ & $\begin{array}{l}\text { One or more antifungal } \\
\text { resistance } \\
(N=26)\end{array}$ & $P$ Value \\
\hline Length of ICU Stay $(n=84)$, Median (IQR) & $18(6.7-37.5)$ & $29(12$ _ 49) & 0.28 \\
\hline Length of hospital stay (days) Median (IQR) & $35\left(17 \_77\right)$ & $51.5\left(21 \_138\right)$ & 0.09 \\
\hline Mortality before first negative culture $\mathrm{n}(\%)$ & $26(27.08)$ & $5(19.23)$ & 0.41 \\
\hline 30-day mortality n (\%) & $54(56.25)$ & $15(57.69)$ & 0.89 \\
\hline
\end{tabular}

Interquartile range (IQR), $\mathrm{N}=$ total number of patients; $\mathrm{n}=$ number of patients or events

and 1996 to 2002 concluded that C. albicans was the most commonly isolated Candida species among patients with candidaemia, followed by C. tropicalis and C. parapsilosis $[8,11]$. Moreover, $C$. albicans remained the dominant isolated species among candidaemia cases in many studies [1, $2,15,16]$. Geographic variation significantly affects the species distribution of Candida [2]. A systematic review summarizing the distribution of Candida species found a high concentration of $C$. albicans isolates in Northern and Central Europe in addition to the USA; however, non- $C$. albicans species were more common in South America, Asia and Southern Europe [17].

Antifungal resistance is a growing primary concern for most healthcare providers. We analysed one hundred and twenty-two Candida BSI cases for resistance. Twenty-one percent of all isolates were resistant to one or more antifungal agents. The patient's risk of developing antifungal resistance was a primary concern in our study. We looked for many possible predisposing factors for drug insensitivity 90 days prior to a candidaemia episode. Patient's previous exposures to broad-spectrum antibiotics, antifungals and corticosteroids were reported; none of the aforementioned risk factors showed a significant association with antifungal resistance in our study despite a positive association of previous antimicrobial exposure to fluconazole resistance among candidaemia in a previous study [18]. However, previous exposure to echinocandins was significantly associated with antifungal resistance among our patients. Many researchers have confirmed that decreased susceptibility to Candida is significantly associated with previous antifungal exposure and an inappropriate prior course of antifungal therapy $[6,19,20]$. In fact, fluconazole exposure was found to be a risk factor for gene mutation and overexposure that leads to future fluconazole-resistant C. parapsilosis [21]. Furthermore, we investigated patient comorbidities and history of invasive procedures or surgery. Many studies addressed drug-resistant candidaemia among cancer patients and considered them a high-risk group [22]. However, our cohort found that antifungal resistance was low among candidaemia patients with non-haematological malignancy. On the other hand, invasive ventilation was significantly associated with drug resistance; this result has been concluded by many researchers, who found that Candida resistance is dramatically higher among critical-care patients [17].

C. parapsilosis is known to have a high affinity for fluconazole, and resistance was absent in an earlier prospective trial [23]. In our study, up to $33 \%$ of $C$. parapsilosis strains were insensitive to fluconazole. Clinical resistance to echinocandins is rare; however, some cases of caspofungin resistance in patients with prolonged exposure to echinocandins have been reported [13]. Our study found few cases of echinocandin resistance. A 2012 US study investigated changes in the incidence of antifungal drug resistance, showing a $7 \%$ resistance to fluconazole and only $1 \%$ to echinocandin [15]. In a US multicentre candidaemia surveillance programme, an increase in the rate of echinocandin resistance was mainly found in C. glabrata, despite it being the preferred treatment [7]. Indeed, patients with fluconazole resistance were at higher risk for C. glabrata-associated echinocandin resistance [16]. The variation in antifungal resistance patterns across geographic regions was addressed in a report on SENTRY antimicrobial surveillance, which observed a detectable resistance to anidulafungin, micafungin, and azoles among isolates of $C$. glabrata from North America [24].

Table 5 Univariate regression analysis for statistically significant risk factors associated with fluconazole resistance C.parapsilosis in patients with candidemia

\begin{tabular}{|c|c|c|c|c|}
\hline & $\begin{array}{l}\text { Fluconazole sensitive C.parapsilosis } \\
(N=20)\end{array}$ & $\begin{array}{l}\text { Fluconazole resistance C.parapsilosis } \\
(N=10)\end{array}$ & OR $(95 \% \mathrm{Cl})$ & $P$ Value \\
\hline Previous Echinocandin Exposure & $5(23.81 \%)$ & $8(80 \%)$ & $12.8\left(2.01 \_81.1\right)$ & 0.005 \\
\hline Blood and Platelet Transfusion & $7(35 \%)$ & $9(90 \%)$ & $14.6\left(1.54 \_138.18\right)$ & 0.006 \\
\hline Invasive Ventilation & $9(42.8 \%)$ & 10 (100\%) & 2.1 (1.31_3.39) & 0.004 \\
\hline
\end{tabular}

Odd ratio $(\mathrm{OR}), \mathrm{N}=$ total number of patients 


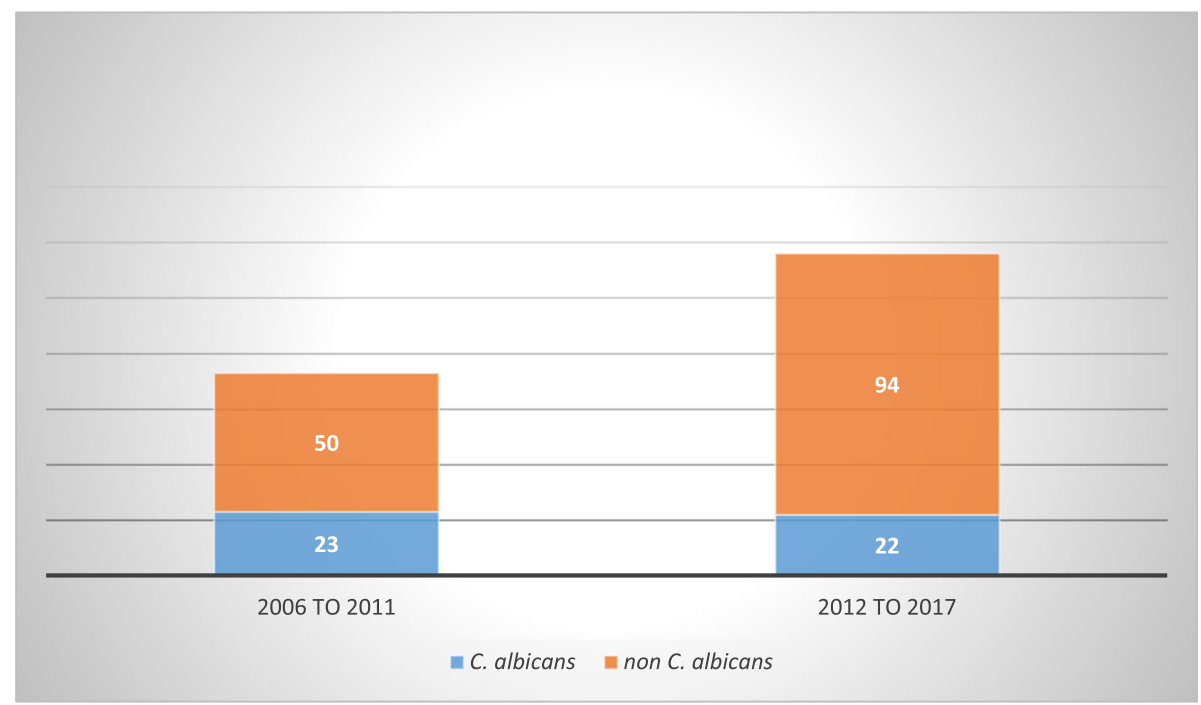

Fig. 1 Distribution of Candida Species over the study period

Candida BSI contributed to a prolonged hospital stay and an increase in the overall healthcare cost [2]. Furthermore, drug resistance was associated with overall mortality $[10,22]$. Despite the increase in length of hospital stay and mortality among our patients with antifungal resistance, the results were not significant.

The retrospective nature of our study could prevent us from identifying all risk factors related to our candidaemia cases. Data on source control and appropriateness of antifungal treatment in terms of timing and dosing of antifungals were not included in our study. Patients who transferred from an outside hospital had no previous records in our system, and risk factors were identified only by physician evaluation notes and nurse documentation. Another limitation is the unavailability of susceptibility data between 2006 and 2011 for all Candida species isolated during our study period, as the request for data was sent out and performed only upon physician request. Although KFSHRC-J is a bone marrow transplantation centre, the number of patients with haematological malignancies involved in our study was small, which prevents us from investigating fluconazole pre-exposure as a risk factor for drug-resistant candidaemia.

\section{Conclusions}

The study identified a high frequency of non-albicans candidaemia. The rise in fluconazole-resistant C. parapsilosis is alarming. More regional data from different hospital settings are needed to allow for a comparison of findings. Our study emphasizes the importance of implementation and compliance with antimicrobial stewardship programmes to control antifungal utilization among hospitalized patients.

\section{Supplementary information}

Supplementary information accompanies this paper at https://doi.org/10. 1186/s12879-019-4710-z.

Additional file 1: Table S1. Resistance pattern among candidemia patients with available susceptibility data by Candida isolates. Table S2. Resistance pattern among candidemia patients with available susceptibility data by antifungal group. Table S3. Multivariate regression analysis for the statistically significant risk factors affecting mortality in patients with antifungal resistance candidemia.

\section{Abbreviations}

BSI: Bloodstream Infection; Cl: Confidence Interval; CLSI: Clinical and Laboratory Standard Institute; CRRT: Continuous Renal Replacement Therapy; GI: Gastrointestinal; HD: Haemodialysis; IC: Invasive Candidiasis; ICU: Intensive Care Unit; IQR: Interquartile Range; KFSH\&RC-J: King Faisal Specialist Hospital and Research Centre, Jeddah; MIC: Minimum Inhibitory Concentration; OR: Odds Ratio; PD: Peritoneal Dialysis; TPN: Total Parental Nutrition; US: United States

\section{Acknowledgements}

Not applicable.

\section{Authors' contributions}

NA and BA Conception and design, data acquisition, analytical plan, interpretation of data, drafting of the manuscript, critical revision of the manuscript for important intellectual content, approval of the final version for publication, and agreement to be accountable for all aspects of the work. HA Conception and design, data acquisition, approval of the final version for publication, and agreement to be accountable for all aspects of the work. AE Conception and design, data acquisition, analytical plan, interpretation of data for the work, approval of the final version for publication, and agreement to be accountable for all aspects of the work. MA Critical revision of the manuscript for important intellectual content, approval of the final version for publication, and agreement to be accountable for all aspects of the work. MQ Critical revision of the manuscript for important intellectual content, approval of the final version for publication, and agreement to be accountable for all aspects of the work. AH Critical revision of the manuscript for important intellectual content, approval of the final version for publication, and agreement to be accountable for all aspects of the work. All authors have read and approved the final manuscript 


\section{Funding}

Pfizer Biopharmaceutical contributed in language editing and articleprocessing charges. There is no role for the funding body in the design of the study and collection, analysis and interpretation of data.

\section{Availability of data and materials}

The datasets used and/or analysed during the current study are available from the corresponding author on reasonable request.

\section{Ethics approval and consent to participate}

The study was approved by the institutional review board of King Faisal Specialist Hospital and Research Centre, Jeddah, Saudi Arabia (IRB\# 17_02).

\section{Consent for publication}

Not applicable.

\section{Competing interests}

AH works at Pfizer, anti infectives.

\section{Author details}

${ }^{1}$ King Faisal Specialist Hospital and Research Center, Jeddah, Saudi Arabia. ${ }^{2}$ King Faisal Specialist Hospital and Research Center, Riyadh, Saudi Arabia.

${ }^{3}$ Anti-infective, Pfizer, Jeddah, Saudi Arabia. ${ }^{4}$ Alfaisal University, Riyadh, Saudi Arabia.

Received: 9 April 2019 Accepted: 17 December 2019

Published online: 17 January 2020

\section{References}

1. Diekema D, Arbefeville S, Boyken L, Kroeger J, Pfaller M. The changing epidemiology of healthcare-associated candidemia over three decades. Diagn Microbiol Infect Dis. 2012;73(1):45-8.

2. Kett DH, Azoulay E, Echeverria PM, Vincent JL. Extended prevalence of infection in ICUSGol. Candida bloodstream infections in intensive care units: analysis of the extended prevalence of infection in intensive care unit study. Crit Care Med. 2011;39(4):665-70.

3. Wisplinghoff $H$, Bischoff $T$, Tallent SM, Seifert $H$, Wenzel RP, Edmond MB Nosocomial bloodstream infections in US hospitals: analysis of 24,179 cases from a prospective Nationwide surveillance study. Clin Infect Dis. 2004;39(3):309-17.

4. Magill SS, Edwards JR, Bamberg W, Beldavs ZG, Dumyati G, Kainer MA, et al. Multistate point-prevalence survey of health care-associated infections. N Engl J Med. 2014;370(13):1198-208.

5. Pappas PG, Kauffman CA, Andes DR, Clancy CJ, Marr KA, Ostrosky-Zeichner $L$, et al. Clinical practice guideline for the Management of Candidiasis: 2016 update by the Infectious Diseases Society of America. Clin Infect Dis. 2016; 62(4):e1-50

6. Garnacho-Montero J, Diaz-Martin A, Garcia-Cabrera E. Ruiz Perez de Pipaon M, Hernandez-Caballero C, Aznar-Martin J, et al. Risk factors for fluconazoleresistant candidemia. Antimicrob Agents Chemother. 2010;54(8):3149-54.

7. Vallabhaneni S, Cleveland AA, Farley MM, Harrison LH, Schaffner W, Beldavs ZG, et al. Epidemiology and Risk Factors for Echinocandin Nonsusceptible Candida glabrata Bloodstream Infections: Data From a Large Multisite Population-Based Candidemia Surveillance Program, 2008-2014. Open Forum Infect Dis. 2015;2(4):ofv163.

8. Akbar DH, Tahawi AT. Candidemia at a university hospital: epidemiology, risk factors and predictors of mortality. Ann Saudi Med. 2001;21(3-4):178-82.

9. Al-Tawfiq JA. Distribution and epidemiology of Candida species causing fungemia at a Saudi Arabian hospital, 1996-2004. Int J Infect Dis. 2007;11(3):239-44.

10. Al Thaqafi AH, Farahat FM, Al Harbi MI, Al Amri AF, Perfect JR. Predictors and outcomes of Candida bloodstream infection: eight-year surveillance, western Saudi Arabia. Int J Infect Dis. 2014;21:5-9.

11. Aljasser AM, Elkhizzi NA. Distribution of Candida species among bloodstream isolates. Saudi Med J. 2004;25(5):566-9.

12. Park BJ, Arthington-Skaggs BA, Hajjeh RA, lqbal N, Ciblak MA, Lee-Yang W, et al. Evaluation of amphotericin B interpretive breakpoints for Candida bloodstream isolates by correlation with therapeutic outcome. Antimicrob Agents Chemother. 2006;50(4):1287-92.

13. Chen SC, Slavin MA, Sorrell TC. Echinocandin antifungal drugs in fungal infections: a comparison. Drugs. 2011;71(1):11-41.
14. Moran C, Grussemeyer CA, Spalding JR, Benjamin DK Jr, Reed SD. Comparison of costs, length of stay, and mortality associated with Candida glabrata and Candida albicans bloodstream infections. Am J Infect Control. 2010;38(1):78-80.

15. Cleveland AA, Farley MM, Harrison LH, Stein B, Hollick R, Lockhart SR, et al. Changes in incidence and antifungal drug resistance in candidemia: results from population-based laboratory surveillance in Atlanta and Baltimore, 2008-2011. Clin Infect Dis. 2012;55(10):1352-61.

16. Pfaller MA, Castanheira M, Lockhart SR, Ahlquist AM, Messer SA, Jones RN. Frequency of decreased susceptibility and resistance to echinocandins among fluconazole-resistant bloodstream isolates of Candida glabrata. J Clin Microbiol. 2012;50(4):1199-203.

17. Falagas ME, Roussos N, Vardakas KZ. Relative frequency of albicans and the various non-albicans Candida spp among candidemia isolates from inpatients in various parts of the world: a systematic review. Int J Infect Dis. 2010;14(11):e954-66.

18. Ben-Ami R, Olshtain-Pops K, Krieger M, Oren I, Bishara J, Dan M, et al. Antibiotic exposure as a risk factor for fluconazole-resistant Candida bloodstream infection. Antimicrob Agents Chemother. 2012;56(5):2518-23.

19. Lortholary O, Desnos-Ollivier M, Sitbon K, Fontanet A, Bretagne S, Dromer F, et al. Recent exposure to caspofungin or fluconazole influences the epidemiology of candidemia: a prospective multicenter study involving 2,441 patients. Antimicrob Agents Chemother. 2011;55(2):532-8.

20. Shah DN, Yau R, Lasco TM, Weston J, Salazar M, Palmer HR, et al. Impact of prior inappropriate fluconazole dosing on isolation of fluconazolenonsusceptible Candida species in hospitalized patients with candidemia. Antimicrob Agents Chemother. 2012;56(6):3239-43.

21. Souza AC, Fuchs BB, Pinhati HM, Siqueira RA, Hagen F, Meis JF, et al. Candida parapsilosis resistance to fluconazole: molecular mechanisms and in vivo impact in infected galleria mellonella larvae. Antimicrob Agents Chemother. 2015:59(10):6581-7.

22. Farmakiotis D, Tarrand JJ, Kontoyiannis DP. Drug-resistant Candida glabrata infection in cancer patients. Emerg Infect Dis. 2014;20(11):1833-40.

23. Canton E, Peman J, Quindos G, Eraso E, Miranda-Zapico I, Alvarez M, et al. Prospective multicenter study of the epidemiology, molecular identification, and antifungal susceptibility of Candida parapsilosis, Candida orthopsilosis, and Candida metapsilosis isolated from patients with candidemia. Antimicrob Agents Chemother. 2011;55(12):5590-6.

24. Pfaller MA, Diekema DJ. Epidemiology of invasive candidiasis: a persistent public health problem. Clin Microbiol Rev. 2007;20(1):133-63.

\section{Publisher's Note}

Springer Nature remains neutral with regard to jurisdictional claims in published maps and institutional affiliations.

Ready to submit your research? Choose BMC and benefit from:

- fast, convenient online submission

- thorough peer review by experienced researchers in your field

- rapid publication on acceptance

- support for research data, including large and complex data types

- gold Open Access which fosters wider collaboration and increased citations

- maximum visibility for your research: over $100 \mathrm{M}$ website views per year

At $\mathrm{BMC}$, research is always in progress.

Learn more biomedcentral.com/submissions 